\title{
Factors influencing the adoption of the World Wide Web for Job-SEeKing in South Africa
}

\author{
Authors: \\ Fernando Pavon ${ }^{1}$ \\ Irwin Brown ${ }^{1}$

\begin{abstract}
Affiliations:
${ }^{1}$ Department of

Information Systems,

University of Cape Town,

South Africa
\end{abstract}

\section{Correspondence to:} \\ Fernando Pavon \\ email: \\ irwin.brown@uct.ac.za \\ Postal address: \\ Department of Information \\ Systems, University of \\ Cape Town, Private Bag, \\ Rondebosch 7701 \\ South Africa
}

\section{Keywords:}

Internet adoption;

job-seeking; South Africa;

recruitment; geographic

barriers

Dates:

Received: 12 Sept. 2009

Accepted: 13 July 2010

Published: 06 Oct. 2010

How to cite this article:

Pavon, F. \& Brown, I.,

2010, 'Factors influencing the adoption of the World Wide Web for job-seeking in South Africa', SA Journal of Information Management 12(1), Art. \#443, 9 pages. DOI: 10.4102/sajim.v12i1.443

This article is available at:

http:/ / www.sajim.co.za

(C) 2010. The Authors.

Licensee: OpenJournals Publishing. This work is licensed under the Creative Commons Attribution License.

\section{ABSTRACT}

In the past decade, the use of the World Wide Web (WWW) as a tool for job-seeking and recruitment has increased globally, changing the dynamics for job-seekers and recruitment organisations. The purpose of this study was to gain greater insight into the factors that influence the adoption of the Internet (WWW) for job-seeking within a South African context. The impact of the Internet (WWW) and newspaper-reading habits on the adoption process was of specific interest. Data was gathered by survey through telephonic interviews with 228 job seekers applying for information technology (IT) work in Cape Town, South Africa. The findings show that the income of a jobseeker influences the favourability of internet facilitating conditions they encounter. Facilitating conditions in turn influence Internet (WWW) usage habits. Such habits influence performance expectancy, effort expectancy and intentions to use the Internet (WWW) for job-seeking. The actual extent of Internet (WWW) usage for job-seeking is positively influenced by these usage intentions and negatively influenced by newspaper-reading habits. These and other findings are discussed and implications drawn.

\section{INTRODUCTION}

The Internet has made a wide range of dynamic Web applications available globally, such as electronic mail, online shopping, collaborative forums, as well as online recruitment and job-seeking (Maran 1998). The use of the WWW for job-seeking is growing and has played a major role in introducing new dynamics into the way employers and employees find one another (Kerrin \& Kettley 2003). This study aims to develop a better understanding of factors that affect the adoption of the WWW for jobseeking within a South African context. Studying the factors that influence use of the WWW for jobseeking in South Africa and how they shape the adoption process, would add to the body of knowledge on global IT adoption. In South Africa, there are unacceptably high unemployment rates and there is much government focus on employment creation. The outcomes of this study could inform strategies aimed at assisting especially those with no access to mainstream print media to seek employment via public access Internet points. The main question driving this investigation is: 'What are the factors that influence the adoption of the WWW for job-seeking?' The factors investigated are performance expectancy, effort expectancy, trust in the Internet, Internet usage and newspaper-reading habits, facilitating conditions and income.

Also of interest is the potential impact of the Internet's global reach and its potential influence in facilitating migration of skills across national borders. Reasons for studying this phenomenon in South Africa specifically were fourfold. Firstly, there has been a dearth of research on the use of the WWW for job-seeking in South Africa and indeed in Africa as a whole(Mbarika et al. 2005).

Secondly, only $9.6 \%$ of the South African population has Internet access (Internet World Stats 2009), hence a small proportion of the employable population. Newspapers are still widely used for job-seeking. It would be of interest to analyse the perceptions and attitudes that would influence the adoption of the WWW for job-seeking. Thirdly, although overall there is a relatively high unemployment rate, there is an acute shortage of skilled professionals in areas such as IT, where the study takes its sample. This could be of interest to recruiting organisations needing to find scarce skills beyond the national borders. The study aims to be useful to both individuals, as well as to organisations as the Internet begins to play a more important role as a job-seeking, as well as a recruitment, tool. In the next section is a general discussion on the WWW and its use for job-seeking. This leads to the establishment of a research framework. The research methodology is then described, followed by a section on the data analysis and results. These results are discussed and implications drawn before the study limitations and ideas for future research are outlined.

\section{INTERNET USE WORLDWIDE}

Out of a total global population of 6.7 billion people, there are just over 1.5 billion Internet users (1 596 270 108) representing $23.8 \%$ of the global population (Internet World Stats 2009). According to Internet World Stats (2009), Asia had the largest number of Internet users in the world with just over 657 million, representing a penetration of only $17.4 \%$. North America had over 251 million Internet users with a penetration of $74.4 \%$, compared to Europe, which had a penetration of $48.9 \%$. While the number of Internet users in Africa has increased to over 54 million, it had the lowest penetration in the world with just $5.6 \%$ of the population accessing the Internet. In South Africa there were about 4.6 million Internet users in 2009, representing just $9.6 \%$ of the population (Internet World Stats 2009). While these statistics point to a digital divide in terms of Internet access, there exist other divides in terms of the quality of access, usage patterns and sophistication of use (Dutta et al. 2005). High-speed, low-cost broadband access is prevalent throughout much of the developed world, while in many developing countries reliable broadband access is both rare and costly (Brown et al. 2007). 


\section{WWW USE FOR JOB-SEEKING}

One of the important uses of the WWW is for job-seeking (Haas et al. 2001; Teo et al. 1999). The number of résumés posted on recruitment websites grew from 100000 in 1995 to 2.5 million in 1998 and by 2000 the number had grown to 7.65 million (Tong \& Sivanand 2005; Simphal 2004). In the United States, about 4 million job-seekers are searching for work on the WWW on a typical day (Barrington \& Shelp 2005), searching through approximately 29 million job adverts online, with 2 million new jobs posted monthly (Jansen et al. 2005). According to Simphal (2004), in Germany, half the population uses the WWW and more than $70 \%$ of it searches for new jobs by using this medium. In the United Kingdom, 7 million job-seekers used the WWW to look for work in 2003 (Simphal 2004). There are more than 3 million job websites worldwide offering online recruitment services (Simphal 2004).

In South Africa there are several successful online recruitment sites (INet-Bridge 2006). The number of jobs advertised by CareerJunction, one of the leading sites, increased by $60 \%$ from 13060 in January 2005 to 20982 in January 2006, while over that same period the number of registered job-seekers increased by $44 \%$ from 326641 to 473313 (Biz-Community 2006). The WWW as a recruiting channel offers several key advantages that encourage adoption by users (Haas et al. 2001). The global reach of the WWW exceeds that of print-based newspapers, making it of benefit to both recruitment companies and job-seekers (Haas et al. 2001).

The ability of the Internet to cross borders has made job-seeking a global activity (Salaff et al. 2004) and has changed the scope for job-seekers, facilitating greater migration (Stevenson 2003). In the United Kingdom, for example, the Internet is actively used to recruit health workers, leading to a significant rise in migration of health professionals from countries such as South Africa, Australia, the Philippines and India to the United Kingdom (Buchan \& Dovlo 2004). Chinese professionals and labourers have found jobs in Canada through the WWW (Salaff et al. 2004). Similarly, as Canada benefits from immigration of talent from other nations, it also loses talent to nations such as the United States (Nakamura \& Davenport n.d.).

The relatively low cost for posting job positions on company websites, compared to the costs for job adverts in print media encourages companies to use corporate portals to post job positions (Färber et al. 2003). The Internet offers convenient accessibility for both the organisation and the job-seeker (Liljander et al. 2002). Online communication may also provide for immediate feedback, resulting in a faster hiring cycle and reducing the cost per hire (Galanaki 2002). Some sites also provide additional benefits such as linking job-postings to information about travel, child-care, schools, housing availability and information to help prepare for transition between jobs (Kilder 1999). Some also incorporate video-conferencing to facilitate online interviews (Lievens et al. 2002). In the next section a research framework is presented for this study.

\section{RESEARCH FRAMEWORK}

The framework used in this study draws from the Unified Theory of Acceptance and Use of Technology (UTAUT) developed by Venkatesh et al. (2003) and the trust and TAM (technology acceptance model) integrated model of Gefen et al. (2003). The UTAUT framework highlights performance expectancy and effort expectancy as major influences on adoption, as well as facilitating conditions (e.g. infrastructure, support services and training) and social influence. The UTAUT model was derived from a consideration of many other technology adoption models such as the TAM, diffusion of innovations theory and theory of planned behaviour (Venkatesh et al. 2003). It was therefore chosen because of its ability to integrate factors from these other models into one unified theory. Despite its comprehensiveness, UTAUT contains no explicit reference to trust. Trust is an important factor in an online context (Gefen et al. 2003). Mistrust of the Internet could have a negative influence in the adoption of the WWW for job-seeking. Gefen et al. (2003) extended the TAM model by adding the trust concept. In this study, we add trust to the UTAUT model for the same reason.

The adoption phenomenon may be country- or culturespecific due to socio-economic factors (Brown et al. 2006; Srite \& Karahanna 2006). Hence in this paper, the effect of income is also investigated. The moderating influence of demographic variables (e.g. age, gender, experience) as suggested by the UTAUT model were not considered in this paper, for the sake of parsimony. Recent research furthermore has shown that as Internet usage gains in global acceptance, the effects of factors such as gender and experience are less pronounced (Zukowski \& Brown 2007).

\section{Performance expectancy of the WWW}

The UTAUT model recognises performance expectancy as encompassing concepts such as perceived usefulness, extrinsic motivation, relative advantage, outcome expectations and task fit (Venkatesh et al. 2003). In some developing countries, the relationship between performance expectancy and IT usage has not always held true, a finding attributed to differing cultural contexts (Anandarajan et al. 2002). A South African study (Brown \& Licker 2003), however, did find a strong relationship between performance expectancy and intentions to use the Internet for learning, providing support for the hypothesis that in this context:

H1: Performance expectancy has a positive effect on the intention to use the WWW for job-seeking.

\section{Performance expectancy of the newspaper}

Using the WWW as a recruiting tool began in the mid-1980s and it has since grown into a worldwide industry (Galanaki 2002). Contrary to earlier hype concerning the Internet, it has not replaced traditional forms of business, but rather provided an alternative channel by which to reach customers. Job-seekers use numerous avenues to find jobs, including newspapers, employment agencies and the Internet (Haas et al. 2001). The widespread prevalence of newspapers and the historical tradition of finding jobs through newspapers results in heightened perceptions of the usefulness (performance expectancy) of the newspaper for job-seeking. The positive perception of newspapers may in turn negatively influence perceptions of jobseekers around the performance expectancy of the Internet for job-seeking. This may be especially true in developing countries such as South Africa, where the Internet is not widely accessible (World Wide Worx 2005). It is hypothesised therefore that

H2: Performance expectancy of the newspaper has a negative effect on the performance expectancy of the WWW for job-seeking.

\section{Effort expectancy of the WWW}

Effort expectancy has been defined as the degree of ease associated with the use of the system (Venkatesh et al. 2003). There have been mixed findings as to the effect of effort expectancy on Internet adoption. These mixed findings have been attributed to the moderating effects of variables such as gender, age, experience, culture and type of task on the strength of relationship (Srite \& Karahanna 2006; Venkatesh et al. 2003). In a developing-countries context, due to factors related to cultural values and lack of experience with technology, this relationship has often been found to hold true (Anandarajan et al. 2002). In addition, it has been shown that effort expectancy influences adoption indirectly through performance expectancy (Venkatesh \& Davis 2000). This holds true in a South African context too (Brown \& Licker 2003). It also has an indirect influence on adoption through trust (Gefen et al. 2003). It is therefore hypothesised that: 
H3a: Effort expectancy (ease of use) of the WWW has a positive effect on the intention to use the WWW for job-seeking. H3b: Effort expectancy (ease of use) of the WWW has a positive effect on performance expectancy of the WWW for job-seeking. H3c: Effort expectancy (ease of use) of the WWW has a positive effect on trust.

\section{Trust in the WWW}

Job-seekers are asked to disclose personal information over the WWW, often to many online job sites. WWW recruitment agencies or hackers could take advantage of online job-seekers through unauthorised use of their personal information. The Internet removes geographic barriers allowing new distant relationships to emerge between recruitment organisations and job-seekers. In these distant relationships, trust in the organisation and the security of the technology are important (Van Slyke et al. 2004). According to McKnight et al. (2002), the degree of trust for a vendor or technology and the uncertainties about security of the medium, such as the perceived risk of hackers stealing personal information, can deter adoption. WWW recruitment sites that rely heavily on personal self-disclosure from the user should take special care of privacy issues. Their ability to build user trust could become a competitive advantage for recruitment sites in the future (Gefen et al. 2003). Users with higher trust levels tend to disclose more sensitive information than users with lower trust levels (Nickel \& Schaumburg 2004). The cultural context may also play a part in moderating the strength of relationship between trust and usage intentions (Srite \& Karahanna 2006). Trust in Internet commerce has been shown to be of key importance for its adoption (Brown et al. 2006). The hypothesis therefore is:

H4: Trust in the WWW has a positive effect on the intention to use the WWW for job-seeking.

\section{WWW usage and newspaper-reading habits}

In order to explain the factors influencing usage behaviour, it is important to consider both conscious intentions as well as subconscious habits (Limayem \& Hirt 2003). Subconscious habits can be a major factor in influencing technology adoption, since behaviour is often habitual and subconscious rather than intentional (Bagozzi et al. 1992). Behaviour is the recurrence of an action until responses become automatic. The frequency of past behaviour reflects habit and directs future behaviour (Oullette \& Wood 1998).

Even though the way jobs are marketed is being transformed by the Internet, recruiters should not ignore traditional media, such as newspapers (Barrington \& Shelp 2005). Haas et al. (2001) found that $44 \%$ of companies indicated that even though the WWW is a valuable tool for recruitment, the print media is still the primary channel for this purpose. Newspapers are still the preferred job-searching method used by the majority in several countries (Barrington \& Shelp 2005; Liang 2005). In developing countries where the WWW is not widely pervasive, the importance of newspapers as a recruitment channel is even more important.

This study explores the general habitual use of the WWW in comparison to newspaper-reading. People who are in the habit of buying the newspaper to read the news or the sport pages are more likely to use the newspaper to look for jobs. They may therefore have more positive perceptions of the performance expectancy of the newspaper. The habitual and frequent reading of newspapers may mean less need to use the WWW for jobseeking, leading to lower intentions to use and actual use of the WWW for this purpose. The hypotheses suggested are:

H5a: Newspaper-reading habits have a positive effect on the performance expectancy of the newspaper for job-seeking.

H5b: Newspaper-reading habits have a negative effect on the intention to use the WWW for job-seeking.

H5c: Newspaper-reading habits have a negative effect on the actual use of the WWW for job-seeking.
Habitual, frequent use of the WWW is associated with intentions to use the WWW for tasks such as banking (Tan \& Teo 2000). There is likely to be greater intention to use the WWW for jobseeking too. Actual usage of the WWW for job-seeking is also more likely as a result of this habit (Limayem \& Hirt 2003). The hypotheses suggested are:

H5d: WWW usage habits have a positive effect on intentions to use the WWW for job-seeking.

H5e: WWW usage habits have a positive effect on actual usage of the WWW for job-seeking.

Beyond the influences on intentions and usage, habitual use of a technology is likely to also influence beliefs and perceptions about that technology (Limayem \& Hirt 2003). The most common beliefs are those concerning performance expectancy and effort expectancy (Venkatesh et al. 2003). Habitual use of the WWW leads to greater familiarity and self-efficacy. Self-efficacy in turn leads to higher levels of ease of use (effort expectancy) and perceived usefulness (performance expectancy) (Lewis et al. 2003). Trust is just as important a belief in an online context (Gefen et al. 2003). Habitual, frequent use of the WWW should boost familiarity with it. Familiarity in turn increases trust (Gefen et al. 2003). The hypotheses suggested are:

H5f: WWW usage habits have a positive effect on performance expectancy of the WWW for job-seeking.

H5g: WWW usage habits have a positive effect on effort expectancy (ease of use) of the WWW for job-seeking.

H5h: WWW usage habits have a positive effect on trust in the WWW for job-seeking.

\section{Facilitating conditions}

Facilitating conditions can be thought of as the organisational and technical infrastructure available to support the users of information technology(Venkatesh et al. 2003). In terms of the WWW, facilitating conditions may refer to the perceived convenience of facilities for accessing the WWW and the sophistication of access method (e.g. some may have WWW access at home or work, using high-speed broadband connections). At the other extreme, some may have access only to public facilities, which may use low-speed, dial-up access. In general, facilitating conditions are most likely to be more favourable in developed countries, due to their sophisticated infrastructure. For example, it was found that in Singapore facilitating conditions were perceived as being more favourable than in South Africa (Brown et al. 2004). These contrasts will have an impact on the ability of users to support their WWW habits. The more favourable the facilitating conditions, the more habitual and frequent the WWW use (Venkatesh et al. 2003). The hypothesis suggested is:

H6a: Favourable WWW facilitating conditions have a positive effect on WWW usage habits.

Reading of news and job-searching are common uses of the WWW. The favourability of WWW facilitating conditions may then reduce the dependence on newspapers for such purposes. The hypothesis suggested is:

H6b: Favourable WWW facilitating conditions have a negative effect on newspaper-reading habits.

\section{Income and Internet access}

Musa et al. (2005) demonstrate that the state of socio-economic development in a region impacts on accessibility and exposure to technologies, which in turn influences their adoption and diffusion. The WWW is a convenient tool for job-seeking but its use may not be spread evenly throughout society (Barrington \& Shelp 2005). In South Africa, only about $9.6 \%$ of the population uses the Internet (Internet World Stats 2009). Part of the reason for this low penetration is the high telecommunications costs, which subsequently impact on the cost of Internet access (Gillwald \& Esselaar 2004) as well as a communication 
backbone, which does not extend across all geographical areas. High telecommunications costs in South Africa have kept the Internet out of reach of the majority of the population (World Wide Worx 2005). Sophisticated, high-speed Internet access is more likely among those with higher incomes, suggesting the following hypothesis:

H7: Income has a positive effect on favourability of WWW facilitating conditions.

In other words, income has a positive effect on an individual's ability to access the WWW. These hypotheses are illustrated in the research framework in Figure 1 below.

\section{RESEARCH PROCEDURE}

A survey strategy was used to collect data via a structured telephonic interview. The telephonic interview approach was chosen because of its natural fit with the interview process of job applicants, given the verbal communication. Telephonic interviews enable a more controlled and consistent way of collecting data by avoiding misunderstandings and spoiled questionnaires in a postal survey. The interviewer is able to ensure that respondents understand the questions and that they respond with due consideration. Telephonic interviews can also produce better quality data and a higher response rate (Venkatesh \& Brown 2001). The study used a cross-sectional timeline, with data gathered at one point in time over a limited period in 2006.

\section{Research instrument}

The research instrument used for this investigation derived measures for performance expectancy, effort expectancy and facilitating conditions from Venkatesh et al. (2003). The trust measure was based on the work of Gefen et al. (2003). The instrument was tested with a pilot sample over an initial period of two weeks to fine-tune the way the questions were phrased. The number of items per construct was reduced to a minimum through the pilot test in order to keep the length of the telephonic interview as concise as possible. Some items required single quantitative entry (e.g. age, expected monthly income, years of work experience, habits). Other items required a choice from a list (e.g. gender, population group, highest qualification, geographic location, where the job was seen). The main set of measures required respondents to supply a ranked response based on a five-point Likert scale, ranging from strongly disagree (1) to strongly agree (5). The measures for performance expectancy ( 3 items), effort expectancy (3 items), trust (3 items), facilitating conditions ( 3 items), intentions to use the Internet for job-seeking (1 item) and actual usage thereof (1 item), employed the Likert scale.

\section{Data collection procedure}

The target population was limited to individuals applying for job positions in Cape Town, but regardless of their geographic location, which allowed for a diversity of respondents. It was expected that the majority of respondents for this study would be from Cape Town, since the advertised jobs were in Cape Town. The strategy used to collect the sample data involved the tracking of responses to adverts for real job-positions placed by a recruiting agent. The recruiting agent was aware of the study and agreed to collaborate. The jobs advertised included positions for software developers, system engineers, salesmen and other professions in the IT sector. The adverts were placed with identical wording in popular local Cape Town newspapers as well as on a popular South African Internet job site. The newspaper and the WWW are the channels most commonly used by Cape Town recruiting agents. Applicants

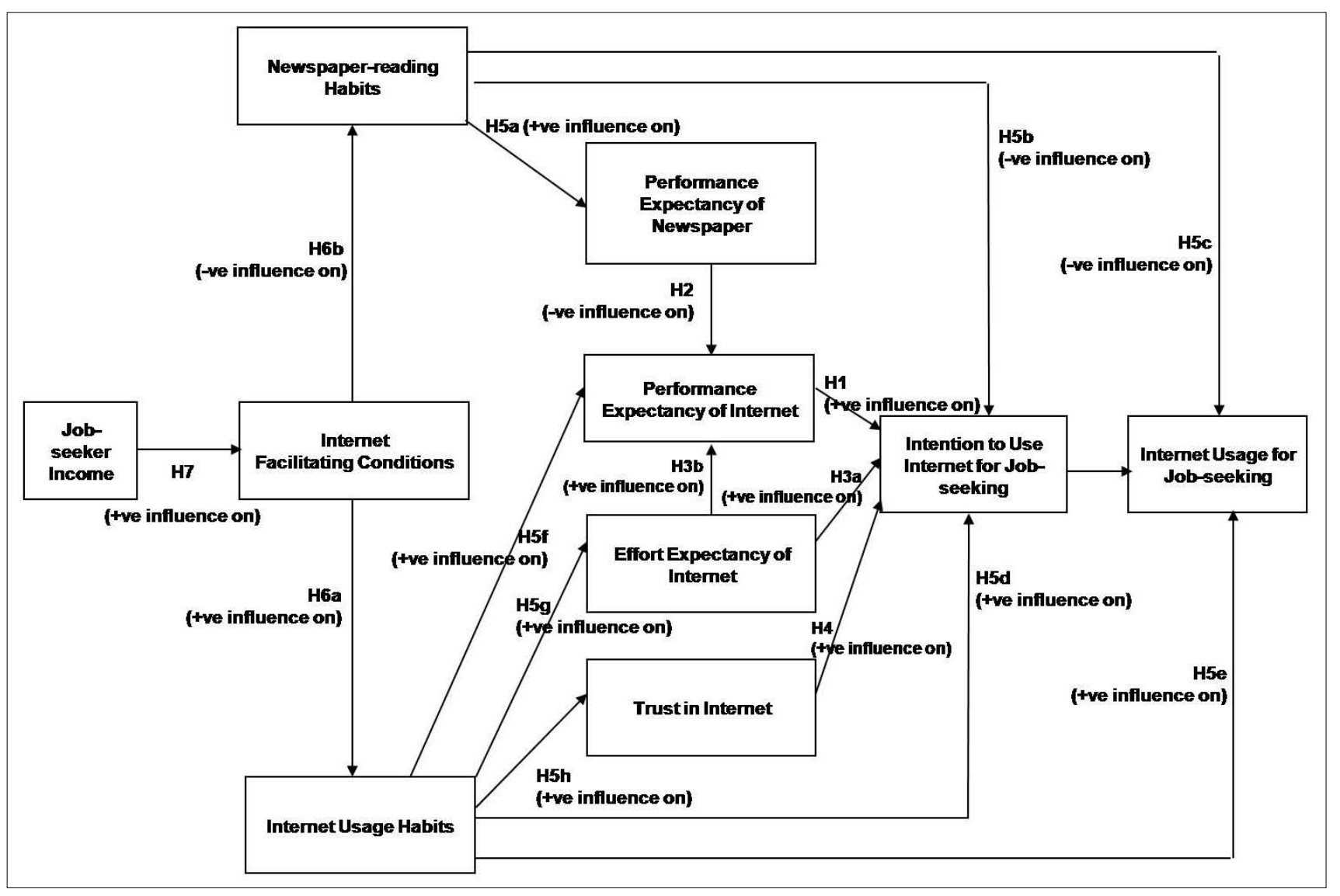

FIGURE 1

Research Framework 
each submitted a résumé. For those who agreed to participate in the study, descriptive data such as age, education and profession were gathered and entered into a spreadsheet. A structured telephonic interview followed where further questions were asked, in accordance with the research instrument in Appendix 1. All applicants who consented voluntarily to the survey interview were included. Over a period of five months in 2006, a total of 40 adverts were placed for 16 job-positions. A total of 228 applicants who replied to the job-adverts were interviewed. A conscious effort was made to ensure that interviewer influence on the interviewee was kept to a minimum by using a single interviewer to do all the interviews and ensuring a consistent tone of voice without emphasis, to avoid leading the interviewee.

\section{DATA ANALYSIS AND RESULTS}

Data analysis was done using a variety of statistical techniques. Descriptive statistics were used to establish the demographic profile of respondents and to determine the correlations between key variables. Constructs were tested for validity and reliability. Factor analysis was used to test the validity of the multiple items and the Cronbach alpha item analysis test was used to test their reliability. Hypotheses were tested through multiple linear regression analysis.

\section{Descriptive statistics}

Respondents held a variety of jobs ranging from support technicians to IT managers. The majority of respondents were from the Western Cape (67.7\%) and from other parts of South Africa $(23 \%)$ while some were from other African countries $(7.5 \%)$ and beyond (1.8\%). Most respondents were under 30 years of age $(76.6 \%)$ and male $(80.5 \%)$. The low number of female respondents corresponds with the low proportion of females in the IT profession (James et al. 2006). All of the major South African population groups were represented (i.e. Black people, Coloured people, White people and Indian people). Table 1 below displays the descriptive statistics for the sample.

Most of the applicants either had a certificate or diploma in IT $(76.4 \%)$ while a few had degree qualifications $(15.3 \%)$. Most of the applicants had fewer than 10 years' work experience (88.2\%) and expected monthly incomes of less than ZAR 10000 (77.4\%). Only $40.8 \%$ of the applicants had Internet access at home with the rest relying on work, place of study, Internet café or other public facility for access. This allowed for variation in facilitating conditions. The majority used the Internet daily (66.5\%). Newspaper-reading habits varied with the largest group being those who read them once a week $(40 \%)$. There was a roughly even split between those who had found the job advertised in the newspaper and those who had found it through the WWW. This variability suited the purpose of the study, which was to ascertain how these factors influence the adoption of the WWW for job-seeking.

\section{Validity and reliability}

Before conducting hypotheses testing, the validity and reliability of the instrument was demonstrated. The validity of multiple item measures was assessed using factor analysis. The following criteria informed the analysis (Lewis-Beck 1994):

- Factor rotation: varimax normalised rotation was performed to obtain a clear pattern of loading.

- Number of factor components: there were four constructs containing multiple items, namely performance expectancy, effort expectancy, trust and facilitating conditions. Four factors were expected.

- Extraction method: the principal components method was used in order to reduce the multidimensional datasets.

- Factor loading: this value was set to 0.4 , since loadings of 0.4 or greater are considered significant (Tan \& Teo 2000).

- Minimum eigenvalue: this value was set to 1.00 .

The items belonging to facilitating conditions (FC), effort expectancy (EE), performance expectancy (PE) and trust (TR)
TABLE 1

Descriptive statistics

\begin{tabular}{|c|c|c|c|c|}
\hline Respondent information & Count & $\%$ & & \\
\hline \multicolumn{5}{|l|}{ Job Title } \\
\hline Support Technician & 45 & 19.7 & & \\
\hline HelpDesk & 38 & 16.7 & & \\
\hline Systems Engineer & 55 & 24.1 & & \\
\hline sW Developer & 34 & 14.9 & & \\
\hline Sales & 15 & 6.6 & & \\
\hline Trainer & 24 & 10.5 & & \\
\hline Management & 4 & 1.8 & & \\
\hline Other & 13 & 5.7 & & \\
\hline \multicolumn{5}{|l|}{ Geographic Location } \\
\hline Cape Town & 153 & 67.7 & & \\
\hline South Africa (other parts) & 52 & 23.0 & & \\
\hline Africa & 17 & 7.5 & & \\
\hline Outside of Africa & 4 & 1.8 & & \\
\hline \multicolumn{5}{|l|}{ Age } \\
\hline $19-25$ & 100 & 45.9 & & \\
\hline $26-30$ & 67 & 30.7 & & \\
\hline $31-35$ & 20 & 9.2 & & \\
\hline $36-40$ & 8 & 3.7 & & \\
\hline$>=41$ & 23 & 10.6 & & \\
\hline \multicolumn{5}{|l|}{ Gender } \\
\hline Female & 43 & 19.5 & & \\
\hline Male & 177 & 80.5 & & \\
\hline \multicolumn{5}{|l|}{ Population Group } \\
\hline Black & 77 & 36.0 & & \\
\hline White & 67 & 31.3 & $\omega$ & \\
\hline Coloured & 66 & 30.8 & D & \\
\hline Indian/Asian & 4 & 1.9 & 읃 & \\
\hline Education & & & $\underline{\underline{0}}$ & \\
\hline High School Matriculation & 18 & 8.3 & $\overline{0}$ & \\
\hline Certificate & 69 & 31.9 & $=$ & $D$ \\
\hline Diploma & 96 & 44.4 & $\equiv$ & $\gtreqless$ \\
\hline Bachelor Degree & 31 & 14.4 & 윽 & $\frac{\bar{\Omega}}{\bar{\Omega}}$ \\
\hline Masters & 2 & 0.9 & $\stackrel{3}{\stackrel{3}{2}}$ & 吕 \\
\hline Monthly Income (ZAR) & & & 윽 & $\vec{\omega}$ \\
\hline$<=5,000$ & 81 & 38.9 & 3 & \\
\hline $5,001-10,000$ & 80 & 38.5 & 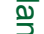 & \\
\hline $10,001-15,000$ & 29 & 13.9 & $\widehat{0}$ & \\
\hline $15,001-20,000$ & 13 & 6.3 & ब(D & \\
\hline$>20,000$ & 5 & 2.4 & 3 & \\
\hline
\end{tabular}

Newspaper

Internet

50.2

49.8

Work Experience

None

$<=5$

$>5$ and $<=10$

$>10$ and $<=15$

$>15$ and $<=20$

$>20$

Internet Usage Habits

Never

Once a month

Once a fortnight

Once a week

Everyday

3.0

3.0

10.5

17.0

66.5

Newspaper-reading Habits

Never

Once a month

Once a fortnight

Once a week

Everyday

\section{5}

3.5

25.5

40.0

18.5

Internet Access

Café/School

Work

Home Dial-up

Home Broadband 


\begin{tabular}{lcccc}
\multicolumn{5}{c}{$\begin{array}{c}\text { TABLE 2 } \\
\text { Factor analysis }\end{array}$} \\
\hline FC1 & Factor 1 & Factor 2 & Factor 3 & Factor 4 \\
FC2 & 0.02 & $\mathbf{0 . 9 6}$ & -0.07 & 0.03 \\
FC3 & 0.04 & $\mathbf{0 . 4 5}$ & 0.09 & -0.01 \\
EE1 & 0.01 & $\mathbf{0 . 9 5}$ & -0.07 & 0.04 \\
EE2 & 0.16 & 0.06 & 0.23 & $\mathbf{0 . 8 9}$ \\
EE3 & 0.09 & 0.01 & 0.01 & $\mathbf{0 . 6 9}$ \\
PE1 & 0.12 & -0.01 & 0.08 & $\mathbf{0 . 7 9}$ \\
PE2 & $\mathbf{0 . 8 6}$ & -0.04 & 0.18 & 0.13 \\
PE3 & $\mathbf{0 . 8 6}$ & 0.08 & 0.06 & 0.15 \\
TR1 & $\mathbf{0 . 8 6}$ & 0.05 & 0.01 & 0.12 \\
TR2 & 0.12 & 0.03 & $\mathbf{0 . 8 8}$ & 0.12 \\
TR3 & 0.09 & -0.12 & $\mathbf{0 . 8 3}$ & 0.12 \\
Expl.Var & 0.03 & 0.09 & $\mathbf{0 . 7 1}$ & 0.04 \\
Prp.Total & 2.28 & 2.06 & 2.08 & 1.99 \\
\hline & 0.19 & 0.17 & 0.17 & 0.17 \\
\hline
\end{tabular}

\begin{tabular}{lll}
\multicolumn{3}{c}{$\begin{array}{c}\text { TABLE 3 } \\
\text { Reliability tests }\end{array}$} \\
\hline Construct & Items & Alpha \\
\hline Facilitating Conditions & 3 & 0.76 \\
Effort Expectancy & 3 & 0.74 \\
Performance Expectancy & 3 & 0.84 \\
Trust & 3 & 0.72 \\
\hline
\end{tabular}

all loaded as expected on separate factors. The measures were

derived from Venkatesh et al. (2003) and Gefen et al. (2003). The results of factor analysis are shown in Table 2 below.

The Cronbach alpha item analysis test was used to assess the reliability of the multiple items within constructs. The results are depicted in Table 3, listing the construct, its items and the corresponding Cronbach alpha score. The scores in all cases are greater than the 0.7 Cronbach alpha value required for a construct measure to be deemed reliable (Stewart \& Segars 2002).

\section{Correlation analysis}

The correlation coefficients between the variables represented in the research framework of Figure 1 are shown in Table 4 below. With the exception of correlations to the dependent variables: intention to use the WWW for job-seeking (Intent) and actual usage (Use), all other coefficients are less than 0.5. This is an indication that they represent distinct factors (Teo et al. 1999).

WWW usage habits (Habit Int) correlated very strongly with performance expectancy of (PE), intentions to use (Intent) and actual usage (Use) of the WWW for job-seeking. These WWW usage habits were negatively associated with newspaperreading habits (Habit News) and performance expectancy of the newspaper (PE News). Effort expectancy (EE) or ease of use of the WWW correlated with PE, Trust and Use. This initial correlation analysis suggests support for the hypotheses. A more rigorous statistical technique called path analysis was carried out for hypothesis testing.

\section{Hypothesis testing}

Path analysis was conducted to test the hypotheses. The results of the path analysis are summarised in Table 5 below. Five from the 18 hypotheses were not supported from the data as follows:

- $\mathrm{H} 3 \mathrm{a}$

- $\mathrm{H} 4$

- $\mathrm{H} 5 \mathrm{~b}$

- $\mathrm{H} 5 \mathrm{e}$

- $\mathrm{H} 5 \mathrm{~h}$

\section{Hypothesis 3a}

Effort expectancy (EE) had no impact on intention to use the WWW for job-seeking (Intent). Venkatesh et al. (2003) demonstrate that the strength of this relationship is moderated by experience. The respondents in this study were mostly ITqualified and experienced in the use of IT and the WWW. Due to this experience, EE was not a major consideration when forming intentions to use the WWW.

\section{Hypothesis 4}

Trust was shown to have no influence on usage intentions (Intent). Trust has been found to influence intentions to use the WWW for tasks such as banking and shopping (Gefen et al. 2003; Kim \& Prabhakar 2004). These tasks are very often characterised by the conduct of financial transactions through the use of credit card details. When using the WWW for jobseeking, such financial transactions may not be required. For this reason, trust may not feature strongly as an influence over usage intentions. Nevertheless, it is recognised that the requirement for transmission of personal/private information when job-seeking still requires some measure of trust (Zukowski \& Brown 2007).

\section{Hypothesis $5 b$}

Newspaper-reading habits (Habit News) were hypothesised as negatively influencing intentions to use the WWW for jobseeking (Intent). This hypothesis was not supported. The effect may be indirect, through performance expectancy (PE).

\section{Hypothesis $5 \mathbf{e}$}

WWW usage habits (Habit Int) had no significant influence on use of the WWW for job-seeking (Use). The effect of this was indirect, through intentions to use the WWW for job-seeking (Intent)

\section{Hypothesis $5 \mathrm{~h}$}

WWW usage habits (Habit Int) had no significant influence on Trust. The reason may be that those who habitually use the WWW may not necessarily be employing it for purposes that require trust (e.g. tasks involving financial transactions or disclosure of personal information). They may hence have fixed trusting beliefs, independent of their WWW usage habits.

Based on the statistical results and hypotheses testing, the amended model supported is shown in Figure 2 below.

TABLE 4

Correlation matrix

\begin{tabular}{|c|c|c|c|c|c|c|c|c|c|c|}
\hline & Income & $\mathrm{FC}$ & Habit Int & Habit News & EE & PE & PE News & Trust & Intent & Use \\
\hline Income & 1.00 & 0.41 & 0.22 & -0.09 & 0.09 & 0.2 & -0.17 & 0.10 & 0.19 & 0.19 \\
\hline FC & - & 1.00 & 0.32 & -0.18 & 0.04 & 0.05 & -0.15 & -0.07 & 0.17 & 0.18 \\
\hline Habit Int & - & - & 1.00 & -0.15 & 0.18 & 0.47 & -0.24 & 0.05 & 0.71 & 0.65 \\
\hline Habit News & - & - & - & 1.00 & 0.01 & -0.13 & 0.37 & 0.16 & -0.07 & -0.21 \\
\hline EE & - & - & - & - & 1.00 & 0.31 & 0.00 & 0.27 & 0.13 & 0.19 \\
\hline PE & - & - & - & - & - & 1.00 & -0.35 & 0.21 & 0.63 & 0.64 \\
\hline PE News & - & - & - & - & - & - & 1.00 & -0.03 & -0.26 & -0.36 \\
\hline Trust & - & - & - & - & - & - & - & 1.00 & 0.14 & 0.13 \\
\hline Intent & - & - & - & - & - & - & - & - & 1.00 & 0.85 \\
\hline Use & - & - & - & - & - & - & - & - & - & 1.00 \\
\hline
\end{tabular}


TABLE 5

Results of hypotheses testing

\begin{tabular}{lllll}
\hline Hypothesis & Relationship & Coefficient & $p$-value & Supported \\
\cline { 2 - 5 } H1 & PE - Intent & 0.41 & $* * *$ & Yes \\
H2 & PE News - PE & -0.26 & $* * *$ & Yes \\
H3a & EE - Intent & -0.11 & Ns & No \\
H3b & EE - PE & 0.24 & $* * *$ & Yes \\
H4 & Trust - Intent & 0.05 & Ns & No \\
H5a & Habit News - PE News & 0.37 & $* * *$ & Yes \\
H5b & Habit News - Intent & 0.06 & Ns & No \\
H5c & Habit News - Use & -0.14 & $* * *$ & Yes \\
H5d & Habit Int - Intent & 0.54 & $* * *$ & Yes \\
H5e & Habit Int - Use & 0.08 & Ns & No \\
H5f & Habit Int - PE & 0.36 & $* * *$ & Yes \\
H5g & Habit Int - EE & 0.18 & $*$ & Yes \\
H5h & Habit Int - Trust & 0.05 & Ns & No \\
H6a & FC - Habit Int & 0.32 & $* * *$ & Yes \\
H6b & FC - Habit News & -0.18 & $*$ & Yes \\
H7 & Inc - FC & 0.31 & $* * *$ & Yes \\
\hline${ }^{*} p<0.05 ;{ }^{* *} p<0.01,{ }^{* * *} p<0.001$ & & &
\end{tabular}

\section{DISCUSSION AND IMPLICATIONS}

This study has demonstrated that despite providing innovative new ways of performing tasks such as shopping, banking and job-seeking, the WWW has not replaced traditional channels for conducting these tasks. The newspaper as a job-seeking channel is still perceived as being useful and continues to be used alongside the WWW. Many studies on technology adoption focus on new technologies without reference to the old methods of accessing information or carrying out tasks. In effect, the reality that both old and new are often used side by side is ignored. To avoid this oversight, this study took into account the fact that newspaper advertising and newspaper-reading habits are still widely prevalent. Variables related to these dimensions were integrated into the model of WWW adoption for job- seeking. Entrenched newspaper-reading habits were found to inhibit the use of the WWW for job-seeking. Entrenched WWW usage habits positively influenced intentions to use the WWW for job-seeking.

Favourable facilitating conditions (viz. access and skill) were found to support WWW usage habits, while negatively impacting on newspaper-reading habits. These facilitating conditions were more favourable among those with higher incomes. Expected income was used as a proxy for income, since actual income was not measured.

Respondent locality was correlated with the media used for finding a job. Those respondents located in Cape Town tended to have used the local newspaper for job-seeking. Respondents from further afield in South Africa and beyond had mostly used the WWW for job-seeking. The WWW serves the purpose of increasing the pool of job applicants beyond the borders of a city, province or country. This allows for recruitment organisations to employ various strategies, depending on local skill availability and demographics. If there is a dearth of skills in South Africa as a whole, the WWW can be used as a primary channel for attracting foreign skills.

\section{LIMITATIONS AND FUTURE RESEARCH}

The study has provided a research framework that integrates income, habits and technology adoption. Since telephonic interviews were used to gather data, the questionnaire had to be short and concise. Several factors were assessed with single items. Future research can build on this study and employ multiple-item measures for factors such as newspaper-reading habits and WWW usage habits to improve instrument reliability and validity.

Job-seekers may adopt strategies for job-hunting, depending on the location of the desired job. For jobs in their same locality

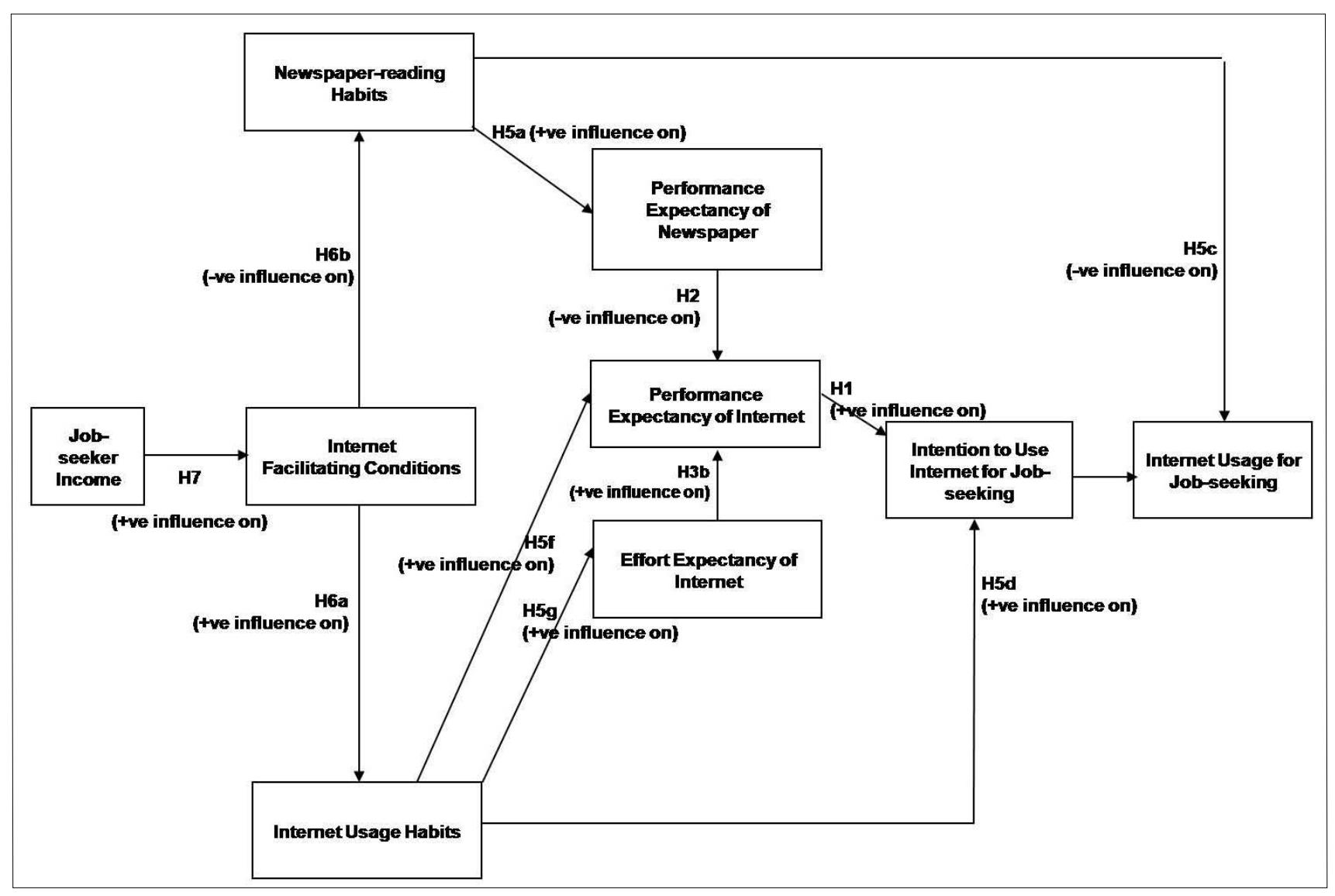

FIGURE 2

Refined Model of Internet 
they may choose to search in newspapers, whereas for jobs in other cities or countries, the WWW may be employed. Some, on the other hand, may have preferences for either the WWW or newspaper channel, regardless of job location. This link between job-seeking behaviour and locality can be investigated in more detail to identify patterns, trends and factors of influence.

This research has investigated the phenomenon of WWW adoption from the job-seeker perspective. Future research might investigate what strategies are used by recruitment organisations to maximise the potential of the WWW and newspaper as recruitment channels, taking into account local and international skill availability.

Future research might attempt to conduct similar studies in other developing countries to investigate the effect of socio-economic conditions on WWW adoption for job-seeking. Comparative studies can also be conducted, where data can be gathered from several countries and the findings from each compared.

The study was based on a theoretical framework derived from UTAUT (Venkatesh et al. 2003) augmented with a trust variable (Gefen et al. 2003) and measures of newspaper-reading and WWW usage habits. The addition of the trust variable did not add to the explanatory power of the model, as none of the hypotheses associated with trust were supported. Performance expectancy and effort expectancy were confirmed as the major influences on WWW adoption for the purposes of job-seeking. Alternative theoretical models, such as uses and gratification theory, or actor-network theory could also be used to provide deeper insight into the processes of adoption of the WWW for job-seeking. Grounded theory methodology might also be used to uncover aspects of adoption not illuminated through theoretical frameworks such as UTAUT.

Finally, the study has focused on the WWW for job-seeking The mobile Internet is increasingly pervasive. Future research might investigate the phenomenon of job-seeking via the mobile Internet.

\section{CONCLUSION}

The WWW has had a major impact on the way companies recruit. Despite this innovation, traditional ways of recruiting, through newspapers, have not become obsolete. Entrenched newspaperreading habits may be hard to dislodge, making the newspaper a preferred option for job-seeking with some. In developing countries such as South Africa, where WWW penetration is low, use of multiple newspaper and WWW channels may be a necessity. In this study, it was found that use of the WWW for job-seeking is influenced positively by intentions to use the WWW for this purpose and negatively by newspaperreading habits. Intentions to use the WWW for job-seeking are influenced by WWW usage habits and performance expectancy of the WWW. This performance expectancy is influenced positively by WWW usage habits, effort expectancy (ease of use) and negatively by performance expectancy of the newspaper. Facilitating conditions positively influence WWW usage habits and negatively influence newspaper-reading habits. Facilitating conditions were found to be influenced by income. The study has contributed towards an understanding of how habits impact on WWW adoption for job-seeking within a South African context. It has provided a basis for similar studies to be conducted in other countries, using telephonic interviews or alternative data gathering techniques. With increased levels of globalisation and flow of skills across borders, an understanding of job-seeking behaviours and habits is highly relevant.

\section{REFERENCES}

Anandarajan, M., Igbaria, M. \& Anakwe, U., 2002, 'IT acceptance in a less-developed country: a motivational factor perspective', International Journal of Information Management $22,47-65$.
Bagozzi, R.P., Davis, F.D. \& Warshaw, P. R., 1992, 'Development and test of a theory of technological learning and usage', Human Relations 457, 660-686.

Barrington, L. \& Shelp, J., 2005, 'Looking for employees in all the right places', The Conference Board: Executive Action Series, No. 173, viewed 24 March 2006, from http://www. exchangemagazine.com/XQuarterly/researchreports/A0173-05-EA.pdf.

Biz-Community, 2006, Job Seekers Go Online, viewed 3 May 2006, from http://www.biz-community.com/ Article/196/22/9345.html.

Brown, I., Collins, T., Maleka, B., Morrison, D., Muganda, N. \& Speight, H., 2007, 'Global diffusion of the Internet XI Internet diffusion and its determinants in South Africa: The first decade of democracy (1994-2004) and beyond', Communications of the Association for Information Systems 19,142-182.

Brown, I., Field, A., Wessels, G. \& Hill, B., 2006, 'Role of uncertainty avoidance and trust in online shopping adoption', Proceedings of the 8th Annual Conference on WWW Applications, 6-8 September 2006, Bloemfontein, South Africa.

Brown, I., Hoppe, R., Mugera, P., Newman, P. \& Stander, A., 2004, 'The impact of national environment on the adoption of Internet Banking - Comparing South Africa and Singapore', Journal of Global Information Management 12(2),1-26.

Brown, I. \& Licker, P., 2003, 'Exploring differences in Internet adoption and usage between historically advantaged and disadvantaged groups in South Africa', Journal of Global Information Technology Management 6(4), 6-26.

Buchan, J. \& Dovlo, D., 2004, 'International Recruitment of Health Workers to the UK: A Report for DFID', Health Policy and Development 2(3), 271-280.

Davis, F., 1989, 'Perceived Usefulness, perceived ease of use, and user acceptance of information technology', MIS Quarterly 13(3), 319-340.

Dutta, A. \& Roy, R., 2005, 'The mechanics of Internet growth: a developing-country perspective', International Journal of Electronic Commerce 9(2), 143-165.

Färber, F., Weitzel, T. \& Keim, T., 2003, 'An automated recommendation approach to selection in personne recruitment', Proceedings of the Ninth Americas Conference on Information Systems, Tampa, Florida, August 4-6, 2003, pp. 2329-2339.

Galanaki, E., 2002, 'The decision to recruit online: A descriptive study', Career Development International 7(4), 243-251.

Gefen, D., Karahanna, E. \& Straub, D. W., 2003, 'Trust and TAM in online shopping: an integrated model', MIS Quarterly 27(1), 51-91.

Haas, C.T., Glover, R.W., Tucker, R.L. \& Terrien, R.T., 2001, 'Impact of the Internet on the Recruitment of Skilled Labour', Center for Construction Industry Studies, Report no. 17, University of Texas at Austin, viewed 24 March 2006, from http://www. ce.utexas.edu/org/ccis/a_ccis_report_17.pdf.

INet-Bridge, 2006, CareerJunction Scoops International Award viewed 3 May 2006, from http://www.mybroadband.co.za/ nephp/?m=show\&id $=2163$.

Internet World Stats, 2009, Usage and Population Statistics, viewed 25 May 2009, from http://www.internetworldstats. com/stats.htm.

Jansen, B. J., Jansen, K.J. \& Spink, A., 2005, 'Using the web to look for work: Implications for online job seeking and recruiting', Internet Research 15(1), 49-66.

Kerrin, M. \& Kettley, P., 2003, e-Recruitment: Is it Delivering? Report 402, Institute of Employment Studies, Brighton, UK.

James, T., Smith, R., Roodt, J., Primo, N. \& Evans, N., 2006, 'Women in the Information and Communication Technology Sector in South Africa', Meraka Institute, viewed 25 May 2009, from http://women-in-ict.meraka.csir.co.za

Kilder, T., 1999, 'The use of the Internet in recruitment - Case study from West Lothian, Scotland', Technovation 20 461-475.

Kim, K. \& Prabhakar, B., 2004, 'Initial trust and the adoption of B2C e-commerce: The case of Internet banking', ACM SIGMIS Database 35(2), 50-64. 
Lewis, W., Agarwal, R. \& Sambamurthy, V., 2003, 'Sources of influence on beliefs about information technology use: An empirical study of knowledge workers', MIS Quarterly 27(4), 657-678.

Lewis-Beck, M., 1994, Factor Analysis and Related Techniques, Sage Publications, Thousand Oaks.

Lievens, F., Van Dam K., \& Anderson, N., 2002, ‘Recent trends and challenges in personnel selection', Personnel Review 31, 580-601.

Liljander, V., Allard C.R., \& Pura, M., 2002, Customer Satisfaction with e-Services: The Case of an Online Recruitment Portal, viewed 24 March 2006, from http://www.shh.fi/ liljande/ vlarmprecr.pdf.

Limayem, M. \& Hirt, S. G., 2003, 'Force of habit and information systems usage: Theory and initial validation', Journal of the Association for Information Systems 4, 65-97.

Maran, R., 1998, Computers $\mathcal{E}$ the Internet, Maran Graphics Inc., Ontario, Canada.

Mbarika, V., Okoli, C., Byrd, T. \& Datta, P., 2005, 'The neglected continent of IS research: A research agenda for Sub-Saharan Africa', Journal of the Association for Information Systems 6(5), 130-170.

McKnight, D.H., Choudhury, V. \& Kacmar, C., 2002, 'Developing and validating trust measures for e-commerce: An integrative typology', Information Systems Research 13(3), 334-359.

Musa, P., Meso, P. \& Mbarika, V., 2005, ‘Toward sustainable adoption of technologies for human development in SubSaharan Africa: Precursors, diagnostics, and prescriptions', Communications of the Association for Information Systems 15, 592-608.

Nakamura, A. \& Davenport, P. n.d., Competing for Talent in an Internet Era, viewed 30 March 2006, from http://www.irpp. org/events/archive/may00/nakamur2.pdf.

Nickel, J. \& Schaumburg, H., 2004, 'Electronic privacy, trust and self-disclosure in e-recruitment', CHI 2004, 1231-1234.

Oullette, J.A. \& Wood, W., 1998, 'Habit and intention in everyday life: the multiple processes by which past behavior predicts future behavior', Psychological Bulletin 124, 54-74.

Salaff, J., Greve, A., Tao, R. \& Chen, R., 2004, 'Can the Internet help? How immigrant women from China get jobs', International Symposium: Log On: Chinese Women and the Cyber Networks, 20-21 October viewed 2 April 2006, from http://web.hku.hk/ anthro/SalaffArent_gender2.pdf.

Simphal, J., 2004, 'Online recruitment in industrialized countries: Drivers, key factors, issues, predictions', Audencia Ecole de Management Nantes, viewed 7 May 2006, from http:// ddata.over-blog.com/xxxyyy/0/00/52/18/erecruitment.pdf.

Stevenson, B., 2003, The Internet, Job Search, and Worker Mobility, viewed 23 March 2006, from http://bpp.wharton.upenn. edu/betseys/InternetSearch.pdf.

Stewart, K. A., \& Segars, A. H., 2002, 'An empirical examination of the concern for information privacy instrument', Information Systems Research 13(1), 36-49.

Srite, M. \& Karahanna, E., 2006, 'The role of espoused national cultural values in technology acceptance', MIS Quarterly 30(3), 679-704.

Tan, M. \& Teo, T., 2000, 'Factors influencing the adoption of Internet banking', Journal of the Association for Information Systems 1(5),1-42.

Teo, T.S.H, Lim, V. \& Lai, R., 1999, 'Intrinsic and extrinsic motivation in Internet usage', Omega, International Journal of Management Science 27, 25-37.

Tong, D.Y.K. \& Sivanand, C.N., 2005, 'E-recruitment service provider's review - International and Malaysian', Employee Relations, 27(1), 103-117.

Van Slyke, C., Belanger, F., Christie, L. \& Comunale, C.L., 2004 'Factors influencing the adoption of web-based shopping: the impact of trust', ACM SIGMIS Database 35(2), 32-49.

Venkatesh, V. \& Brown, S.A., 2001, 'A longitudinal investigation of personal computers in homes: Adoption determinants and emerging challenges', MIS Quarterly 25(1), 71-102.

Venkatesh, V. \& Davis, F.D., 2000, 'A theoretical extension of the Technology Acceptance Model: Four longitudinal field studies', Management Science 46(2), 186-204.
Venkatesh, V., Morris, M.G., Davis, G.B. \& Davis, F.D., 2003, 'User acceptance of information technology: Toward a unified view', MIS Quarterly 27(3), 425-478.

World Wide Worx, 2005, Great Expectations Stall on the Internet, viewed 23 April 2006, from http://www.theworx.biz/ access $05 . h$ tm

Zukowski, T. \& Brown, I., 2007, 'Examining the influence of demographic factors on Internet users' information privacy concerns', Proceedings of SACSIT 2007 Annual Research Conference of the South African Institute of Computer Scientists and Information Technologists, 2-3 October 2007, Sunshine Coast, South Africa.

\begin{tabular}{l} 
APPENDIX 1 \\
\hline Research instrument \\
Demographic Information \\
D1. What is your job title? \\
D2. What is your age? \\
D3. What is your gender? (male or female) \\
D4. What is your expected income? \\
D5. What is your ethnicity? (Black, Coloured, Indian, White, Other, prefer not to \\
answer) \\
D6. Where do you live at the moment? (Cape Town, South Africa, Africa, World) \\
D7. How many years experience do you have in the IT industry? \\
D8. What is your highest qualification? (Matric, Certificate, Diploma, Degree, \\
Masters) \\
D9. Can you name any websites that you could use to help you find work?
\end{tabular}

\section{Performance Expectancy}

PE1. The Internet is a useful tool for job-seeking. (Strongly agree - 5, 4, 3, 2, 1 Strongly disagree)

PE2. Using the Internet will help you to find a job more quickly. (Strongly agree -5 , $4,3,2,1$ - Strongly disagree)

PE3. Using the Internet is more effective than the newspaper for job-seeking (Strongly agree - 5, 4, 3, 2, 1 - Strongly disagree)

PE4. The newspaper is a useful tool for job-seeking. (Strongly agree $-5,4,3,2$, 1 - Strongly disagree)

\section{Effort Expectancy}

EE1. The Internet is easy to understand. (Strongly agree - 5, 4, 3, 2, 1 - Strongly disagree

EE2. Internet job-sites are easy to use. (Strongly agree - 5, 4, 3, 2, 1 - Strongly disagree)

EE3. The Internet is easy to interact with. (Strongly agree - 5, 4, 3, 2, 1 - Strongly disagree)

\section{Facilitating Condition}

FC1. You have the necessary resources to enable you to access the Internet. (Strongly agree - 5, 4, 3, 2, 1-Strongly disagree)

FC2. You have the knowledge and training available to learn to use the Internet. (Strongly agree - 5, 4, 3, 2, 1 - Strongly disagree)

FC3. How do you access the Internet? (5 - Broadband, 4 - Dial-up, 3 - Place of work, 2 - Cybercafé or community centre, 1 - No access)

Habit

H1. How often do you use the Internet? (every day, once a week, once a fortnight, once a month, never)

H2. How often do you read the newspaper? (every day, once a week, once a fortnight, once a month, never)

Trust

T1. Online recruitment websites can be trusted with your personal information. (Strongly agree - 5, 4, 3, 2, 1- Strongly disagree)

T2. You feel secure from hackers when using the Internet. (Strongly agree - 5, 4, 3 , 2, 1 - Strongly disagree)

T3. You trust the Internet for making purchases with your credit card. (Strongly agree $-5,4,3,2,1$ - Strongly disagree)

\section{Behavioural Intention}

BI. You intend to use the Internet to look for work in the future. (Strongly agree $-5,4$, $3,2,1$ - Strongly disagree)

Actual Use

AU1. You always use the Internet to look for work. (Strongly agree - 5, 4, 3, 2, 1 Strongly disagree) 